AIAA Paper 99-1336

\title{
ANALYSIS OF DISCRETE-SOURCE DAMAGE PROGRESSION IN A TENSILE STIFFENED COMPOSITE PANEL
}

\author{
John T. Wang", Christine G. Lotts", and David W. Sleight" \\ NASA Langley Research Center \\ Hampton, VA
}

\begin{abstract}
$\underline{\text { Abstract }}$
This paper demonstrates the progressive failure analysis capability in NASA Langley's COMET-AR finite element analysis code on a large-scale built-up composite structure. A large-scale five stringer composite panel with a 7-in. long discrete source damage was analyzed from initial loading to final failure including the geometric and material nonlinearities. Predictions using different mesh sizes, different saw cut modeling approaches, and different failure criteria were performed and assessed. All failure predictions have a reasonably good correlation with the test result.
\end{abstract}

\section{$\underline{\text { Introduction }}$}

For composite material to be successfully used in primary aircraft structures such as wings and fuselages, one of the design requirements is a two-bay crack damage tolerance capability. The two-bay crack, representing a discrete source damage caused by fragments from a failed engine, spans from one bay to the other bay and severs one stiffener. To meet the damage tolerance requirement, this two-bay damage cannot propagate through the adjacent stiffeners when the load level is below seventy percent of the design limit load. ${ }^{1}$

Analyses and tests have been conducted to investigate the damage progression and residual strength of stiffened composite panels with this type of damage. ${ }^{1,2}$ However, robust analysis tools which can predict the material and geometrically nonlinear behavior of composite structures are still lacking. Good correlation between analytical results and experimental data for a large-scale stiffened

\footnotetext{
* Aerospace Engineer, CSB/SD, Member AIAA

+ Aerospace Engineer, CSB/SD

Copyright $(01999$ by the American Institute of Aeronautics and Astronautics, Inc. No copyright is asserted in the United States under title 17, U.S. Code. The U.S. Government has a royalty-free license to exercise all rights under the copyright claimed herein for Governmental Purposes. All rights are reserved by the copyright owner.
}

composite structure with discrete source damage has yet to be achieved.

In the past few years Moas ${ }^{3}$, Pifko ${ }^{4}$, Sleight ${ }^{5}$, and Sleight et $\mathrm{al}^{6}$ implemented a robust damage progression analysis capability into the NASA Langley's research finite element code, COMET$\mathrm{AR}^{7}$. This code has an excellent nonlinear analysis capability and can perform adaptive mesh refinement. The damage progression analysis procedure, widely used by other researchers ${ }^{7-14}$, evaluates failure ply-byply and discounts the material properties for the failed ply. Other damage progression analysis approaches, such as the one based on continuum damage mechanics ${ }^{15,16}$, can also be implemented. Using the COMET-AR's nonlinear solution procedure, the analysis can include both the material nonlinearity due to the degradation of material properties and the geometric nonlinearity due to the large deformations.

Progressive damage analysis is computationally intensive. Failures are evaluated at each through-thethickness integration point of every element, and material properties for each failed integration point need to be updated. Furthermore, to account for the geometrical nonlinearity and material degradation, the Newton-Raphson method ${ }^{17}$ is used, and failure evaluations are performed at each converged load step to update the tangent stiffness matrix. Because of the complexity of the progressive failure analysis procedure for large-scale structures, it has rarely been successfully demonstrated and published.

The objective of this study is to demonstrate that this newly implemented damage progression analysis procedure can be successfully used for analyzing a large-scale composite structure with discrete source damage. Analytical predictions of a stiffened panel 
are compared with the panel's test data to demonstrate that reasonable test and analysis correlation could be obtained. This panel was designed and fabricated by the McDonnell-Douglas Aerospace (MDA), now The Boeing Company, under NASA Langley Research Center's "Innovative Composite Aircraft Primary Structure Program," and tested at NASA Langley Research Center ${ }^{1}$. Another problem analyzed demonstrates that crack turning at the stiffener flanges could also be predicted. The crack turning at the flanges is a desired failure mechanism for an aircraft structure with a two-bay crack since the damage propagation can be confined within the two already damaged bays.

A few technical issues, that are often encountered in the damage progression analysis of a large-scale stiffened composite structure with a discrete source damage, are also discussed. These technical issues are the effect of mesh size on the damage progression prediction, the effect of modeling the crack tips on the damage progression prediction, and the effect of using different failure criteria with their corresponding material degradation models on the damage progression prediction.

By studying these technical issues, the usefulness of this progressive damage analysis method and its limitations can be better understood and defined.

\section{Failure Criteria}

Three failure criteria were used in this study including the Maximum Stress ${ }^{18}$, the Hashin criterion $^{19}$, and the Hashin-Rotem criterion $^{20}$. The Maximum Stress criterion is a limit criterion in which the stress interaction effect is not included for failure prediction. The Hashin and the Hashin-Rotem criteria maintain some stress interactions. These failure criteria can be expressed as follows;

\section{Maximum Stress criterion}

Fiber failure:

$$
\frac{\sigma_{11}}{X} \text { or } \frac{\sigma_{11}}{X} \geq 1
$$

Transverse matrix cracking:

$$
\frac{\sigma_{22}}{Y} \text { or } \frac{\sigma_{22}}{Y^{\prime}} \geq 1
$$

Shear matrix cracking:

$$
\frac{\left|\tau_{12}\right|}{S} \geq 1
$$

$\underline{\text { Hashin criterion }}$

Fiber failure (tension):

$$
\left(\frac{\sigma_{11}}{X}\right)^{2}+\left(\frac{\tau_{12}}{S}\right)^{2} \geq 1
$$

Fiber failure (compression):

$$
\frac{\sigma_{11}}{X} \geq 1
$$

Matrix failure (tension:

$$
\left(\frac{\sigma_{22}}{Y}\right)^{2}+\left(\frac{\tau_{12}}{S}\right)^{2} \geq 1
$$

Matrix failure (compression):

$$
\frac{\sigma_{22}}{Y^{\prime}}\left[\left(\frac{Y^{\prime}}{2 S_{T}}\right)^{2}-1\right]+\left(\frac{\sigma_{22}}{2 S_{T}}\right)^{2}+\left(\frac{\tau_{12}}{S_{A}}\right)^{2} \geq 1
$$

\section{Hashin-Rotem criterion}

Fiber failure (tension or compression):

$$
\frac{\sigma_{11}}{X} \text { or } \frac{\sigma_{11}}{X} \geq 1
$$

Matrix failure (tension):

$$
\left(\frac{\sigma_{22}}{Y}\right)^{2}+\left(\frac{\tau_{12}}{S}\right)^{2} \geq 1
$$

Matrix failure (compression):

$$
\left(\frac{\sigma_{22}}{Y}\right)^{2}+\left(\frac{\tau_{12}}{S}\right)^{2} \geq 1
$$

The principal stresses and strength properties of a lamina used in the three failure criteria are defined as

$\sigma_{11}, \sigma_{22}$, and $\tau_{12}:$ stress in the fiber direction, stress in the transverse-to-the fiber direction, and the in-plane shear stress, respectively.

$X$ and $X^{\prime}$ : tensile and compressive strengths in fiber direction.

$Y$ and $Y^{\prime}$ :tensile and compressive strengths in transverse direction. 
$S_{A}$ and $S_{T}$ : in-plane shear strength and transverse shear strength, respectively.

All three-failure criteria have the capability of identifying failure modes of a lamina. In the progressive damage analysis, the identification of failure modes in a lamina is critical for the continuation of progressive analysis. Failure modes will be used to determine which material properties of the failed lamina need to be degraded for the next step of the analysis. Many other failure criteria ${ }^{21,22}$ can also used for the damage progression analysis.

\section{Material Degradation Models}

The material degradation model used in this study for each aforementioned failure criterion is listed in Table 1. For example, when fiber failure is detected, the moduli $E_{11}$ and $G_{12}$ and the Poisson's ratio $v_{12}$ are degraded according to the Maximum Stress Criterion. Similarly, when matrix failure or shear failure are detected, the moduli $E_{22}$ and $G_{12}$ and the Poisson's ratio $v_{12}$ are degraded.

The material properties can be degraded slowly or can be instantaneously reduced to zero if failure occurs. In this study, the $E_{11}, E_{22}$, and $G_{12}$ were instantaneously reduced to $1,000 \mathrm{psi}$ and $v_{12}$ was instantaneously reduced to 0.01 . Retaining small values of material properties was found to help avoid numerical difficulties in the nonlinear analysis solution.

Failure in an element is quantified as the percent of ply-integration point failure in that finite element. The COMET-AR element used for this analysis is $\mathrm{ES5/E} 410$, which is a 4-node quadrilateral element. Each element has five Gauss quadrature points. Through-the-thickness integrations of the element use three integration points for each ply in the laminate. The total ply-integration points in an element are $5 \times 3 \times$ Number-of-Plies. In this paper, a damaged element means that more than $60 \%$ of its plyintegration points have failed, resulting in a very small load carrying capability of this element.

\section{$\underline{\text { Panel Description }}$}

The MDA panel in testing is shown in Figure 1. The applied load was introduced to the panel through two metallic test fixtures, one at the top and one at the bottom. The test fixtures were bolted to the skin bays such that the stiffeners and flanges were not directly loaded. Dimensions of the panel are shown in Figure 2. The length and the width of the panel are 80 and 40 inches, respectively. The height of the stiffeners is $2.30 \mathrm{in}$. and the width of the flanges is $3.2 \mathrm{in}$. The stringer spacing is $8.0 \mathrm{in}$. This panel has five-stringers and a 7-in. saw-cut to simulate a discrete source damage. The saw-cut severs the center stringer and 3.5 in. of skin on either side of the stringer centerline. In the analysis, moduli and strengths for a typical AS4/3501-6 unidirectional lamina were used. They are:

$$
\begin{array}{ll}
E_{1}=15.04 \mathrm{msi} & X=182.0 \mathrm{ksi} \\
E_{2}=1.60 \mathrm{msi} & X^{\prime}=-138.97 \mathrm{ksi} \\
G_{12}=0.8 \mathrm{msi} & Y=9.94 \mathrm{ksi} \\
\vee_{12}=0.34 & Y^{\prime}=-31.04 \mathrm{ksi} \\
\text { Ply Thickness }=0.0064 \mathrm{in} . & S_{A}=S_{T}=17.52 \mathrm{ksi}
\end{array}
$$

The lay up sequences are $\left[45 /-45 / 0_{2} / 90 / 0_{2} /-45 / 45\right]_{6}$ for the skin, $\left[45 /-45 / 0_{2} / 90 / 0_{2} /-45 / 45\right]_{8}$ for the stiffener, and $\left[45 /-45 / 0_{2} / 90 / 0_{2} /-45 / 45\right]_{4}$ for the stiffener flange. The panel was fabricated by a stitched/RFI (resin film infusion) process. Because the stitching can prevent the delamination failure mode, the present analysis procedure, which did not evaluate the delamination failure mode, was considered to be appropriate for predicting the damage progression in the stitched panel.

\section{$\underline{\text { Nonlinear Analysis }}$}

The nonlinear behavior of a composite structure can be caused by geometrical nonlinearity, material nonlinearity, or a combination of both. Geometrical nonlinearity is associated with a large deformation ${ }^{23}$. Material nonlinearity can occur when the stress-strain relations become nonlinear due to ply failure. In the progressive failure analysis of a composite structure with a large deformation, both the geometrical nonlinearity and material nonlinearity need to be included.

The assembled nonlinear finite element system equation is

$$
\left[K_{t}(\{D\})\right]\{D\}=\{P\}
$$

where $\{D\}$ is the displacement vector, $\{P\}$ is the applied load vector, and $\left[K_{t}(\{D\})\right]$ is the tangent 
stiffness matrix which depends on the nodal displacements.

The Newton-Raphson method ${ }^{17,23}$ was used to solve this nonlinear system equation (Equation 11). The damage evaluation and the recomputation of $\left[K_{t}\right]$ were performed at every converged load step. Equilibrium between the internal force vector, left side of the system equation which was computed by using the new $\left[K_{t}\right]$, and the external force vector, right side of the system equation, was reestablished by repeating the nonlinear analysis and failure evaluation at the current load step. After the equilibrium was established, the nonlinear analysis advanced to the next load step.

\section{$\underline{\text { Finite Element Models }}$}

Three finite element models were created. They are a coarse mesh crack model, a fine mesh crack model, and a fine mesh slit model. The three models are shown in Figures 3 to 5, respectively. These models represent the fourth quadrant of the panel shown in Figure 2. In the first two models, the width of the saw-cut was neglected and the discrete source damage was modeled as a sharp crack. In the third model, the width of the saw-cut was modeled as a 0.2-in. wide slit with round tips. The radius of the round tip is 0.1 in. Boundary conditions used in the analyses are shown in Figures 3 to 5. Symmetry boundary conditions were applied at the uncracked portion of the top edge and the right edge, free boundary conditions were applied at the left edge, and a uniform longitudinal displacement load was applied at the bottom edge of these finite element models. Note that loads were applied on the skin bays only and not applied on the blades and the flanges to simulate the actual test loading conditions.

In the region surrounding the crack, the mesh size of the fine mesh crack model is half the mesh size of the coarse mesh crack model. The width of the coarse mesh is $0.2 \mathrm{in}$. while the width of the fine mesh is 0.1 in. For the fine mesh slit model with a round tip, the mesh size at the tip is much less than the 0.1 in. while the mesh size away from the crack tip is the same as the fine mesh crack model. The coarse mesh crack model contains 1,302 nodes and 1,238 quad element, the fine mesh crack model contains 3,248 nodes and 3,163 quad elements, and the fine mesh slit model contains 3,348 nodes and 3,254 quad elements.
Results from the coarse mesh crack model and the fine mesh crack model were used to study the mesh size effect on the damage progression. The issue of modeling the saw cut as a sharp crack or as a slit with round tips was studied by using the two fine mesh models. The issue of how different failure criteria and their corresponding material property degradation models could affect the damage progression results was studied by using the results from all three models. The Maximum Stress, Hashin, and HashinRotem criteria and their corresponding material property degradation models were used in the analyses. To demonstrate the potential of using this damage progression analysis capability, results predicted with these three models were compared with the MDA panel test results to illustrate that a reasonably good analysis and test correlation can be obtained. To demonstrate that crack turning at the flange can be predicted by using this progressive failure analysis capability, the fine mesh crack model was used for the crack turning study.

\section{Damage Progression Analysis Results}

During the nonlinear analysis, a longitudinal displacement was applied on the bottom edge of the panel's skin bays in a small increment of 0.002 in. The applied load level, that is the reaction load for each load step, was computed. Applied load levels for the advancing damage to reach the flange predicted by three different finite element models and three different failure criteria are reported in Table 2. A typical damage growth plot is shown in Figure 6. Note that a damaged element means that more than $60 \%$ of its ply-integration points failed. The damage growth can also be visualized from a deformed plot as shown in Figure 7. The distortion and the large deformation of the damaged elements ahead of the crack can be observed. The deformed shape shown in Figure 7 was obtained by mirroring the deformed shape of a quarter model. Results for the Figures 6 and 7 were obtained by analyzing the fine mesh model with the Hashin-Rotem failure criterion. Degradation of material properties of the damaged elements may result in an ill-conditioned tangent stiffness matrix, and large deformations of these damaged elements may also cause divergence problems in the nonlinear analysis. An approach used by Chamis et $\mathrm{al}^{13}$ to adaptively remove the severely damaged elements from the model may prevent the divergence problem. This approach will be incorporated into COMET-AR code in the future. 


\section{$\underline{\text { Mesh size effect }}$}

Table 2 shows that the applied load levels predicted by the coarse mesh crack model are higher than those predicted by the fine mesh crack model. Since the high stress field exists at the crack tip, the finer mesh predicted higher element stresses, which resulted in an earlier damage growth initiation in the fine mesh crack model.

As illustrated in Figure 8, a slower damage growth for the coarse crack model was found. At a load level about 485 kips, the damage growth for the fine mesh was $1.1 \mathrm{in}$. while the damage growth for the coarse mesh was 0.8 in. Note the damage growth length is defined as the length of a damage zone measured from the original crack tip along the crack line. For the damage propagating to the edge of the flange of the adjacent stiffener as shown in Figure 9, the applied loads for the coarse mesh crack model and the fine mesh crack model were 588 and 564 kips, respectively. A $4.3 \%$ higher load was needed for the coarse mesh crack model. Results in Figures 8 and 9 were obtained by using the Hashin-Rotem failure criterion.

\section{Crack tip modeling}

Results in the second row and the third row of Table 2 show how the crack tip modeled can affect the damage progression. The damage progression results obtained from this fine mesh slit model were compared with the results obtained from the fine mesh crack model. The applied load levels predicted by the fine mesh crack model were higher than the fine mesh slit model with a round tip. The difference may be caused by a much earlier damage initiation for the fine mesh slit model due to a very fine mesh used to model the round tip.

As illustrated in Figure 10, at a load level about 360 kips; the damage growth length for the fine mesh slit model was 0.6 in. while for the fine mesh crack model it was 0.2 in. For the damage progression to the edge of the adjacent stiffener as shown in Figure 11 , the applied loads for the fine mesh slit model and the fine mesh crack model the were 522 and 564 kips, respectively. An $8.0 \%$ higher load was needed for the fine mesh crack model. Figures 10 and 11 were obtained by using the Hashin-Rotem failure criterion.

\section{$\underline{\text { Effect of failure criterion used }}$}

Results in Table 2 show that the damage growth depends on the failure criterion and its corresponding degradation model used. Comparing the damage progression results predicted by the Maximum Stress criterion, the Hashin criterion and the Hashin-Rotem criterion, the highest load level for every mesh model used was predicted by the Maximum Stress failure criterion. The lowest load level for every mesh model used was predicted by the Hashin failure criterion. As mentioned before, the Maximum Stress failure criterion is a limit criterion in which the failure of a ply is predicted by comparing the principal stresses in that ply with its principal strengths, separately. In the Hashin criterion and the Hashin-Rotem criterion, some stress interactions are maintained. The shear stress can contribute to the fiber and matrix failure for the Hashin failure criterion while the shear stress can only contribute to matrix failure for the HashinRotem criterion.

As illustrated in Figure 12, the load levels predicted by using the fine mesh slit model with the Hashin and the Maximum Stress criteria were 487 kips and 547 kips, respectively. The difference is about $12.3 \%$. For the same model, the load level predicted by the Hashin-Rotem was 522 kips as shown in Figure 11, which is $4.6 \%$ below the applied load level predicted by the Maximum Stress failure criterion.

\section{Comparison with test result}

The test result documented in Reference 1 shows that at a load level of 521 kips $(96 \%$ of design limit load), the damage progression reached to the flange of the adjacent stiffeners. Note that this five-stringer panel meets the discrete source damage requirement, which requires the damage progression confined within the two damage bays for the applied load below 380 kips ( $70 \%$ of the design limit load).

As discussed in the previous three subsections, the mesh size, the different modeling approach of the saw-cut, and the selection of the failure criterion can have some effects on the predicted damage growth results. In general, the applied loads predicted by all the models using the Maximum Stress, the Hashin and the Hashin-Rotem criteria are considered within an acceptable range from the test result. Higher loads were predicted when the coarse mesh crack model or the Maximum Stress criterion was used. The worst 
prediction is about $16.3 \%$ above the test result when the coarse mesh model and the Maximum Stress criterion were used. The best prediction is about $0.2 \%$ above the test result when the fine mesh slit model and the Hashin-Rotem criterion were used.

\section{Potential for crack turning prediction}

For a stiffened composite panel to meet the twobay damage tolerance requirement, the crack growth needs to be contained within the two damaged bays and can not propagate through the adjacent flanges. It is desired that the crack turns when it reaches the adjacent stiffener flanges rather than penetrating the flanges. It is expected that if a high strength material system is used in the stiffener flanges, the crack can be stopped and forced to propagate parallel to the stiffener. In this study, an assumed high strength material system was used for the flange. Indeed, the crack changes direction at the edge of the flange region as shown in Figure 13. In this study the Hashin-Rotem failure criterion was used.

\section{Concluding Remarks}

Analytical results documented in this paper demonstrate that the recently implemented progressive failure analysis capability in COMET-AR can be a useful tool for the damage tolerance analysis of large-scale built-up composite structures. A largescale five stringer composite panel with a 7-in. long discrete source damage was analyzed. Geometrical and material nonlinearities were considered in the analysis. Predictions using different mesh sizes, different saw cut modeling approaches, and different failure criteria were performed. All the predictions have a reasonably good correlation with the test result.

A few technical issues, which can affect the damage progression predictions, were also discussed. Analysts need to be aware of these issues and exercise the progressive damage growth analyses with care.

The first technical issue is the effect of the mesh size. A coarse mesh crack model and a fine mesh crack model were used to study the mesh size effect. It is found that for the damage to propagate to the same distance, a higher applied load was needed for coarse mesh model.
The second technical issue is the effect of crack tip model. The discrete source damage can be modeled as a sharp crack or as a slit with round tips. A fine mesh crack model and a fine mesh slit model were analyzed. Results show that the damage initiation is much earlier in the slit model resulting in a longer damage growth when both models were subjected to the same load level. This indicates that the configuration of the saw-cut needs to be carefully modeled.

The third technical issue is the effect of different failure criteria. Three different failure criteria were used to study how the damage progression can be affected by the selection of failure criterion. For the same amount of damage growth, the applied load level predicted by the Maximum Stress criterion is higher than that predicted by the Hashin and the Hashin-Rotem criteria. The Hashin-Rotem criterion provided the closest match with the experimental results.

Further improvement of the accuracy of predictions is needed before analysis simulations can be used to replace costly structural tests. This may be achieved by the advancement of micromechanics to better understand the failure mechanisms, more advanced failure analysis procedures, and incorporating reliability analysis in the failure prediction. Nevertheless, this progressive failure analysis capability should be able to provide pretest predictions for damage tolerance tests of aircraft structures. These predictions are vital for the selection of a test machine, fixture design, and the set-up of test data acquisition system.

\section{Acknowledgement}

The authors would like to acknowledge Dawn Jegley of NASA Langley for providing the panel configurations and David Xue of the Analytical Services and Materials Inc. for providing the analytical support. 


\section{References}

1. Sutton, J. Kropp, Y., Jegley, D. and BanisterHendsbee,D. "Design, Analysis, and Tests of Composite Primary Wing Structure Repairs," Fifth NASA/DoD Advanced Composites Technology Conference, Seattle, Washington, August 22-25, 1994, NASA-CP 3294, Vol. 1, Part 2, Compiled by Davis, J.G., Jr., Shuart, M.J., and Bowles, D.E., May 1995.

2. Bernhard, D., Murphy, D. P., Ilcewicz, L., Walker, T., "Damage Tolerance Analysis of composite Transport Fuselage Structure," $35^{\text {th }}$ AIAA/ASME/ASCE/AHS/ASC Structures, Structural Dynamics, and Materials Conference, Hilton Head, SC, AIAA Paper No. 94-1406, April 18-20, 1994.

3. Moas, E., "Progressive Failure Analysis of Laminated Composite Structures", Ph.D. Dissertation, Virginia Polytechnic Institute and State University, 1996.

4. Pifko, A. B., "Novel Composites for Wing and Fuselage Applications," Work performed under NASA Contract NAS1-18784, Grumman Aerospace Corporation, 1992-1994.

5. Sleight, D. W., "Progressive Failure Analysis Methodology for Laminated Composite Structures," M.S. Thesis, Old Dominion University, August 1996.

6. Sleight, D. W., Knight, N. F., Jr., and Wang, J. T., "Evaluation of a Progressive Failure Analysis Methodology for Laminated Composite Structures," 38th AIAA/ASME/ASCE/AHS/ASC Structures, Structural Dynamics, and Materials Conference, Kissimmee, Florida, AIAA Paper No. 97-1187, April 7-10, 1997.

7. Moas, E., Editor, COMET-AR User's Manual, NASA CR-97-206248, 1997.

8. Chang, F. K., and Chang, K. Y., "A Progressive Damage Model for Laminated Composites Containing Stress Concentrations," Journal of Composite Materials, Vol. 21, September 1987, pp. 834-855.

9. Tan, Seng C., "A Progressive Damage Model for Composite Laminates Containing Openings,"
Journal of Composite Materials, Vol. 25, May 1991, pp. 556-577.

10. Ochoa, O. O., and Engblom J. J., "Analysis of Failure in Composites," Composites Science and Technology, Vol. 28, 1987, pp. 87-102.

11. Lee, J. D., "Three Dimensional Finite Element Analysis of Damage Accumulation in Composite Laminate," Computers and Structures, Vol. 15, 1982, pp. 335-350.

12. Shahid, I., "Progressive Failure Analysis of Laminated Composites Subjected to In-Plane Tensile and Shear Loads," Ph. D. Dissertation, Stanford University, CA, April 1993.

13. Chamis C. C. and Murthy P. L. N., Progressive Fracture of polymer Matrix Composite Structures: A new Approach, NASA TM-105574, 1992.

14. Irvine, T. B. and Ginty, C. A., "Progressive Fracture of Fiber composites," Journal of Composite Materials, Vol. 20, 1986, pp. 166-184.

15. Allen, D. H., Groves, S. E., and Harris, C. E., "A Thermomechnical constitutive Theory for Elastic Composites with distributed damage- part I: Theoretical Development," International Journal of Solids and Structures, Vol. 23, No. 9, 1987, pp. 1301-1318.

16. Allen, D. H., Groves, S. E., and Harris, C. E., "A Thermomechnical constitutive Theory for Elastic Composites with distributed damage- part II: Application to Matrix Cracking in Laminated composites," International Journal of Solids and Structures, Vol. 23 No. 9, 1987, pp. 1319-1338.

17. Crisfield, M. A., Non-linear Finite Element Analysis of Solids and Structures, Vol. 1, ISBN 0471-92956-5 (v. 1), John Wiley \& Sons Ltd., 1991.

18. Jones, R. M., Mechanics of Composite Materials, ISBN 0-07-032790-4, Scripta book Co., Washington, DC, 1975.

19. Hashin, Z., "Failure Criteria for Unidirectional Fiber Composites," ASME Journal of Applied Mechanics, Vol. 47, June 1980, pp. 329-334.

20. Hashin, Z., and Rotem, A., "A Fatigue Failure Criterion for Fiber Reinforced Materials," Journal 
of Composite Materials, Vol. 7, October 1973, pp. 448-464.

21. Nahas, M. N., "Survey of Failure and Post-Failure Theories of Laminated Fiber-reinforced Composites," Journal of Composites Technology \& Research, Vol. 8, No. 4, Winter 1986, pp. 138153.
22. Ochoa, O., and Reddy, J. N., Finite Element Analysis of Composite Laminates, Kluwer Academic Publishers, Dordrecht, The Netherlands, 1992.

23. Zienkiewicz, O. Z., and Taylor, R. L., The Finite Element Method, fourth edition, Vol. 2, ISBN 007-084175-6 (V. 2), McGRAW-HILL Book Company (UK) Ltd., 1989.

Table 1. Material Degradation Models

\begin{tabular}{llll}
\hline Failure Criterion & Fiber failure & Matrix failure & Shear failure \\
\hline Maximum Stress & $E_{11}, G_{12}, v_{12}$ & $E_{22}, G_{12}, v_{12}$ & $E_{22}, G_{12}, v_{12}$ \\
Hashin & $E_{11}, G_{12}, v_{12}$ & $E_{22}, G_{12}, v_{12}$ & Not applicable \\
Hashin-Rotem & $E_{11}, G_{12}, v_{12}$ & $E_{22}, G_{12}, v_{12}$ & Not applicable
\end{tabular}

Table 2. Applied Loads for Damage Progression to Reach the Adjacent Flange

\begin{tabular}{|l|l|l|l|}
\hline FEM Models & $\begin{array}{l}\text { Maximum Stress } \\
\text { Criterion }\end{array}$ & Hashin Criterion & Hashin-Rotem Criterion \\
\hline $\begin{array}{l}\text { Coarse mesh crack } \\
\text { model }\end{array}$ & 606 kips*(16.3\%)** & 571 kips (9.6\%) & 588 kips(12.9\%) \\
\hline Fine mesh crack model & 591 kips (13.4\%) & 553 kips (6.1\%) & 564 kips(8.3\%) \\
\hline Fine mesh slit model & 547 kips (5.0\%) & 487 kips (-6.5\%) & 522 kips(0.2\%) \\
\hline
\end{tabular}

* Thousand pounds.

**\% difference relative to the test data of 521 kips.

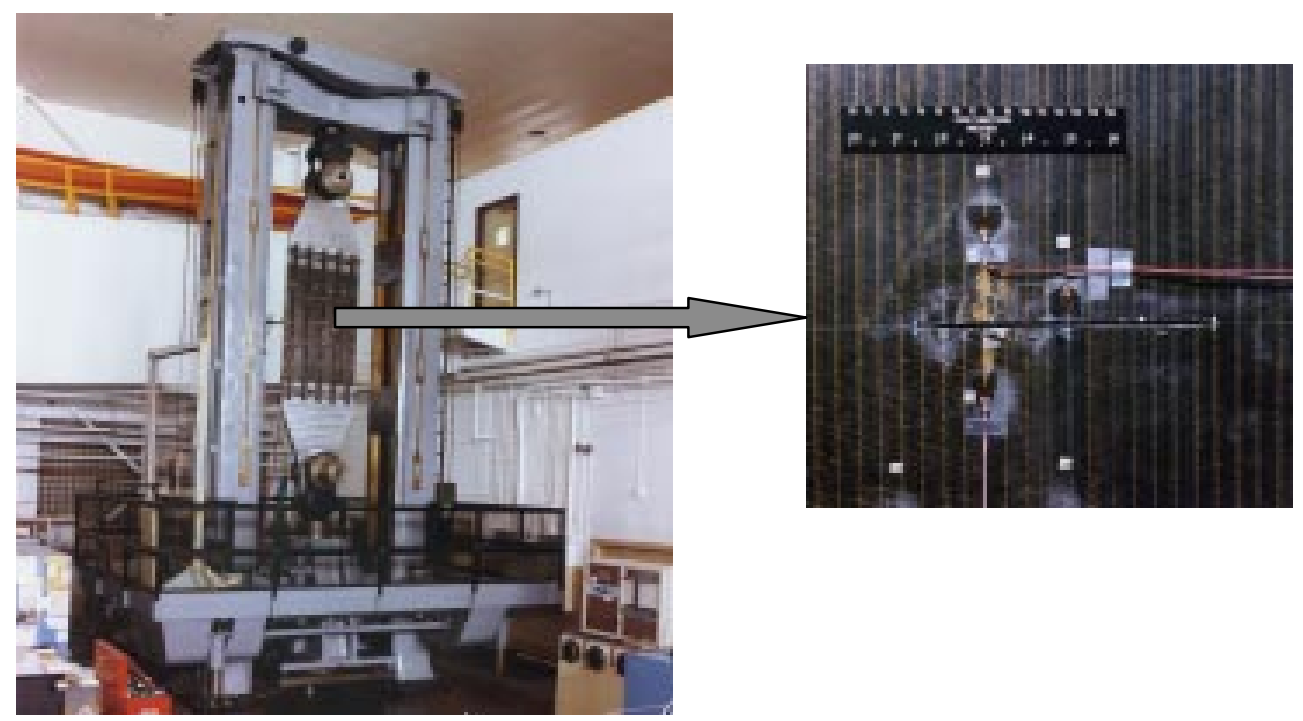

Figure 1. A five-stringer composite panel with a discrete source damage in testing. 
AIAA Paper 99-1336

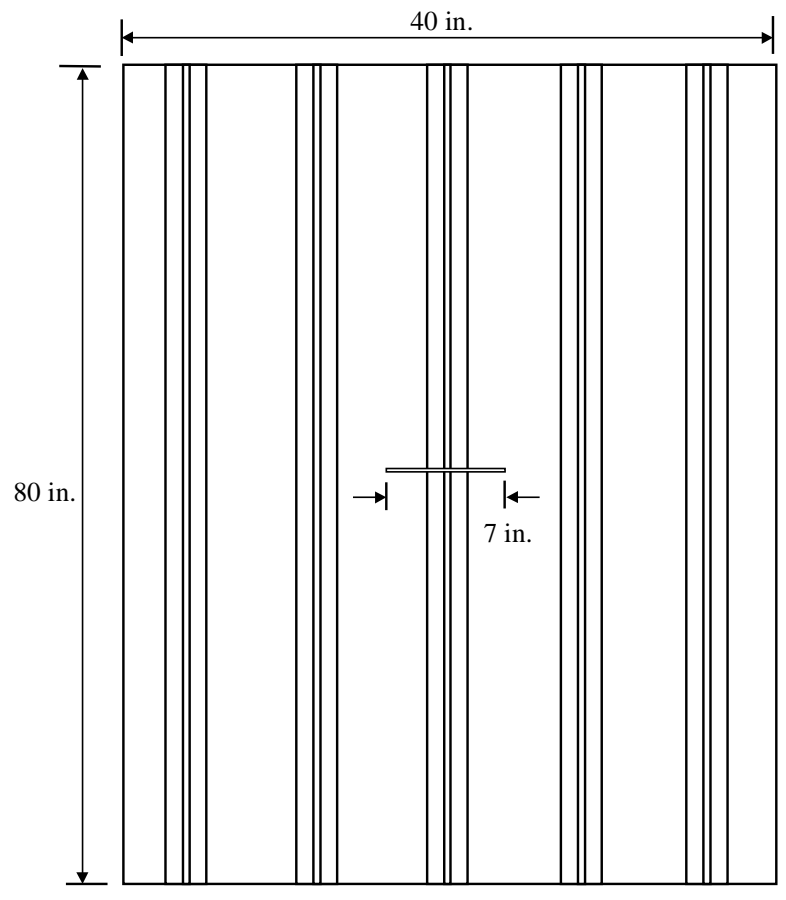

Figure 2. Geometry of the five-stringer composite panel.

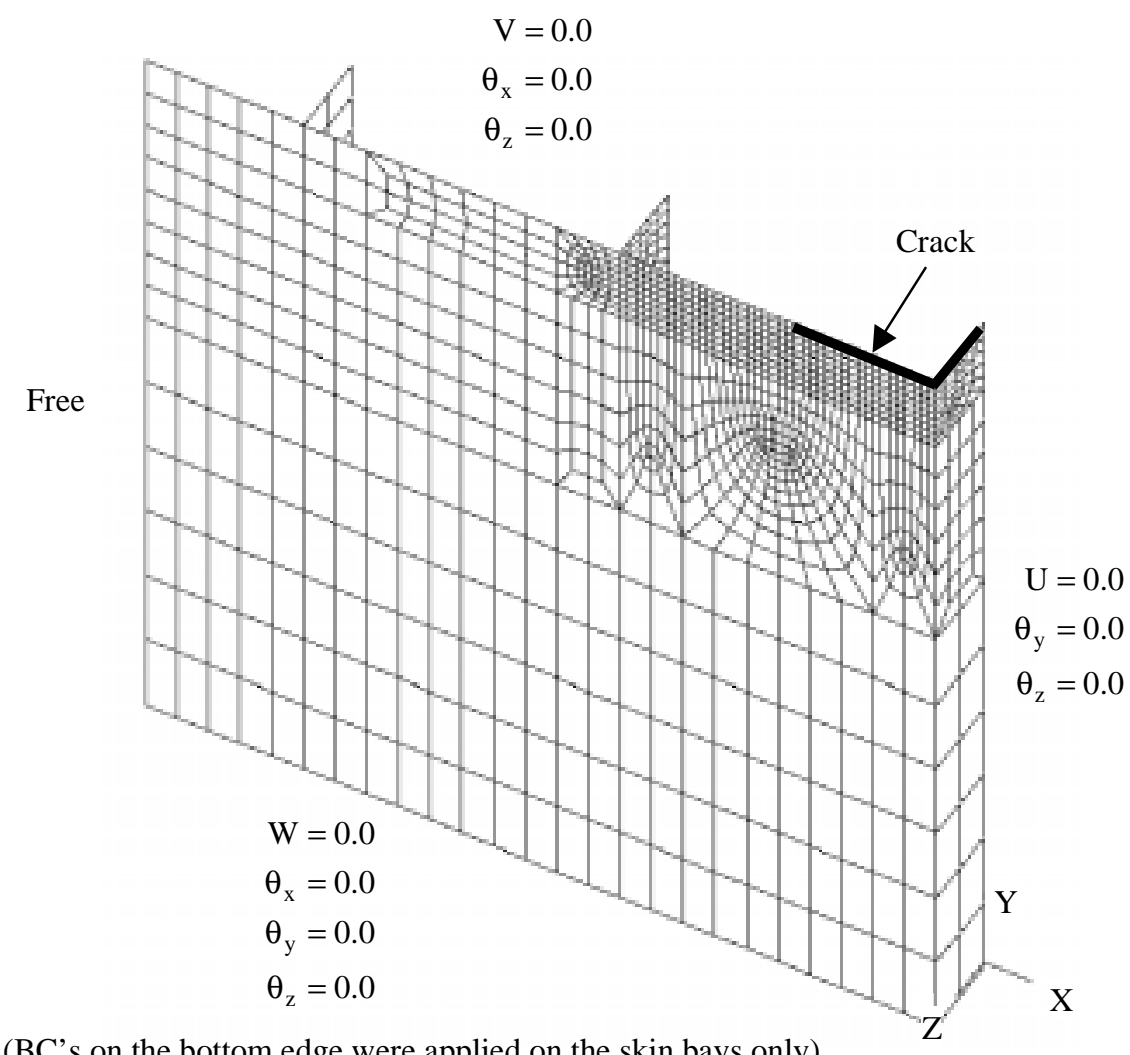

(BC's on the bottom edge were applied on the skin bays only)

Figure 3. The coarse mesh crack model. 
AIAA Paper 99-1336

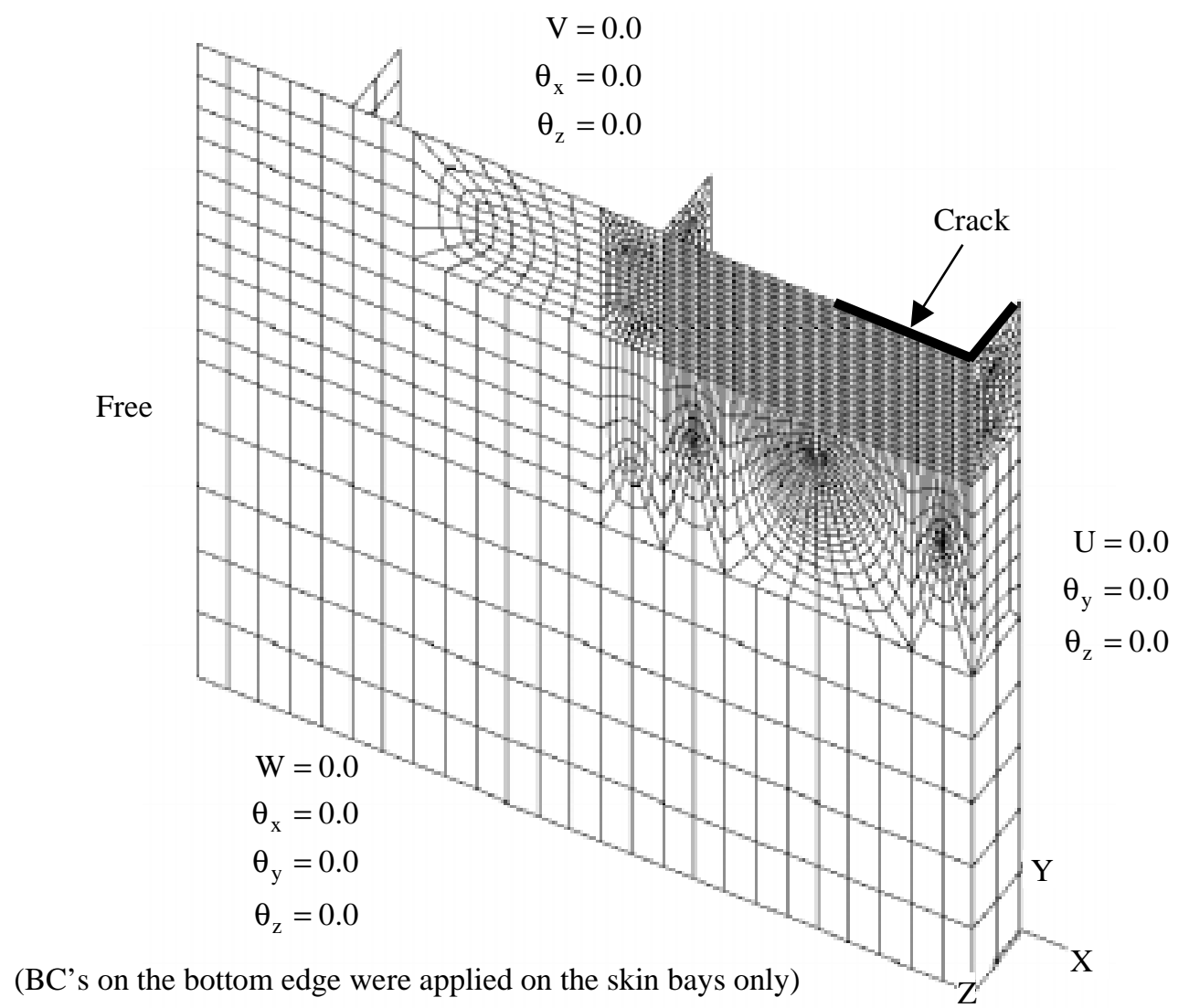

Figure 4. The fine mesh crack model.

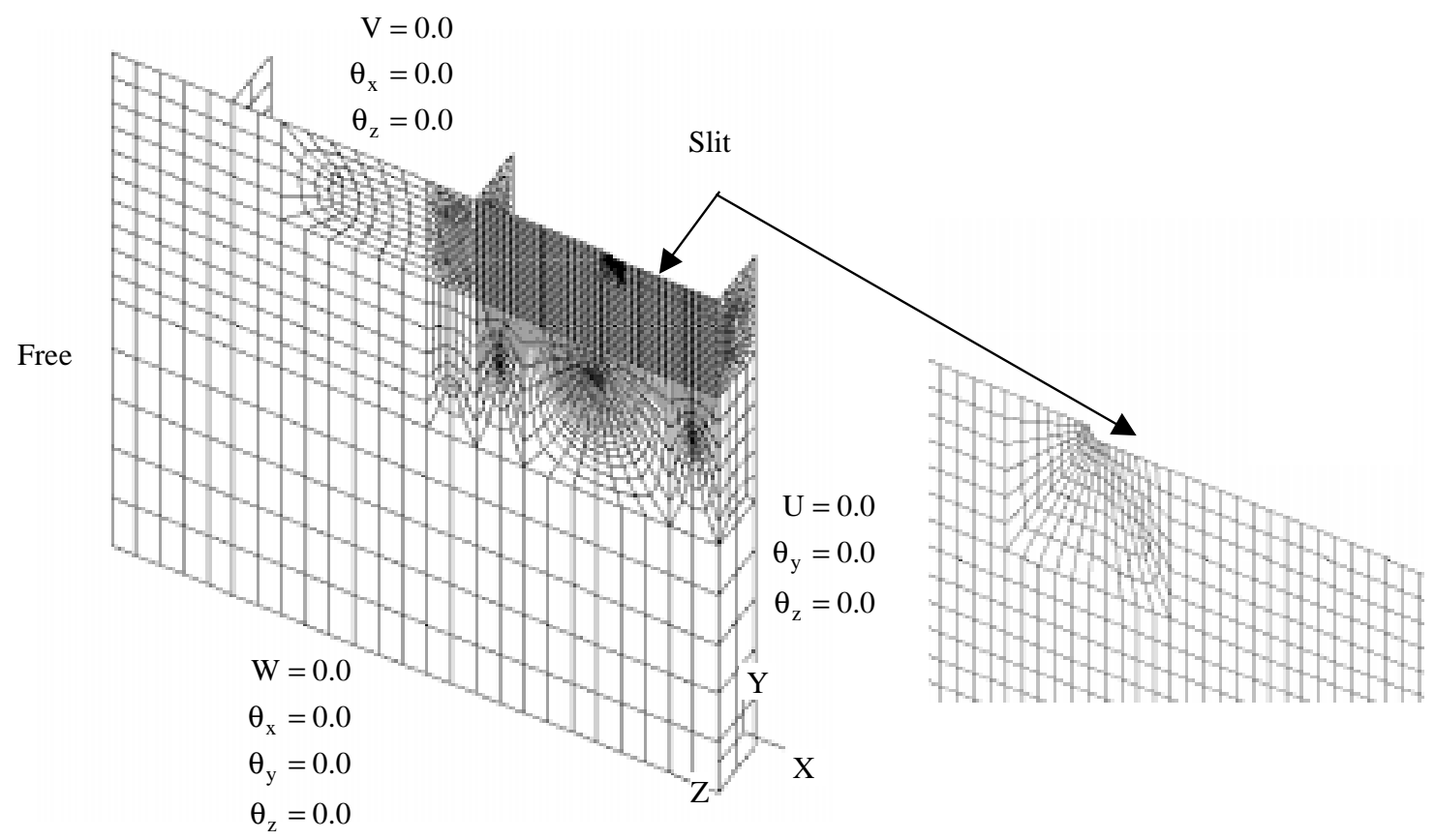

(BC's on the bottom edge were applied on the skin bays only)

Figure 5. The fine mesh slit model with a round tip. 
AIAA Paper 99-1336

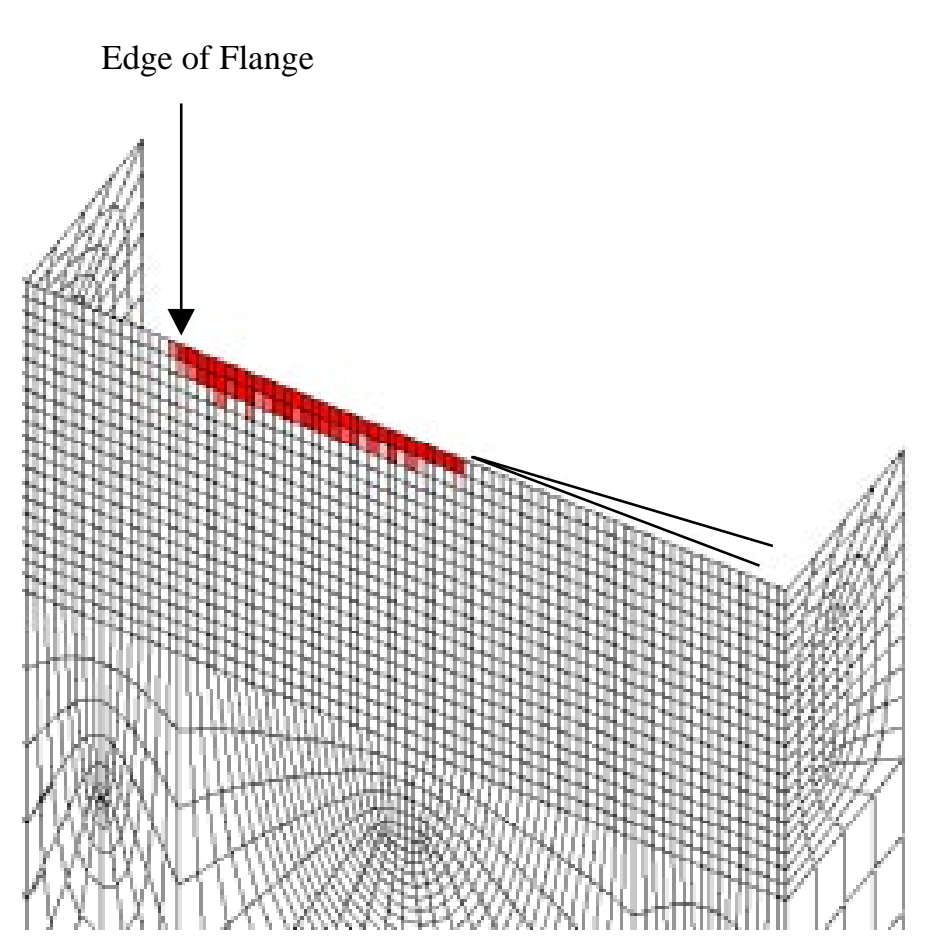

Max $=100 \%$ ply failure

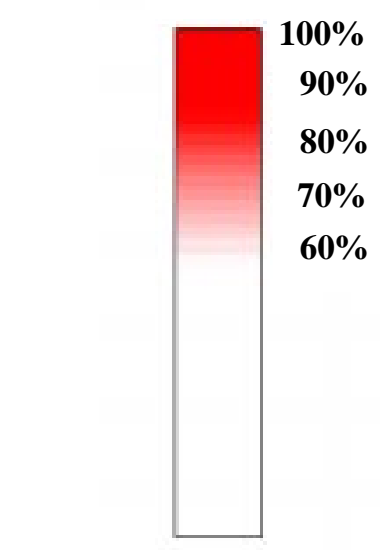

Min $=0 \%$ ply failure

Figure 6. Damage reaching the edge of the adjacent flange at a load level of 564 kips.

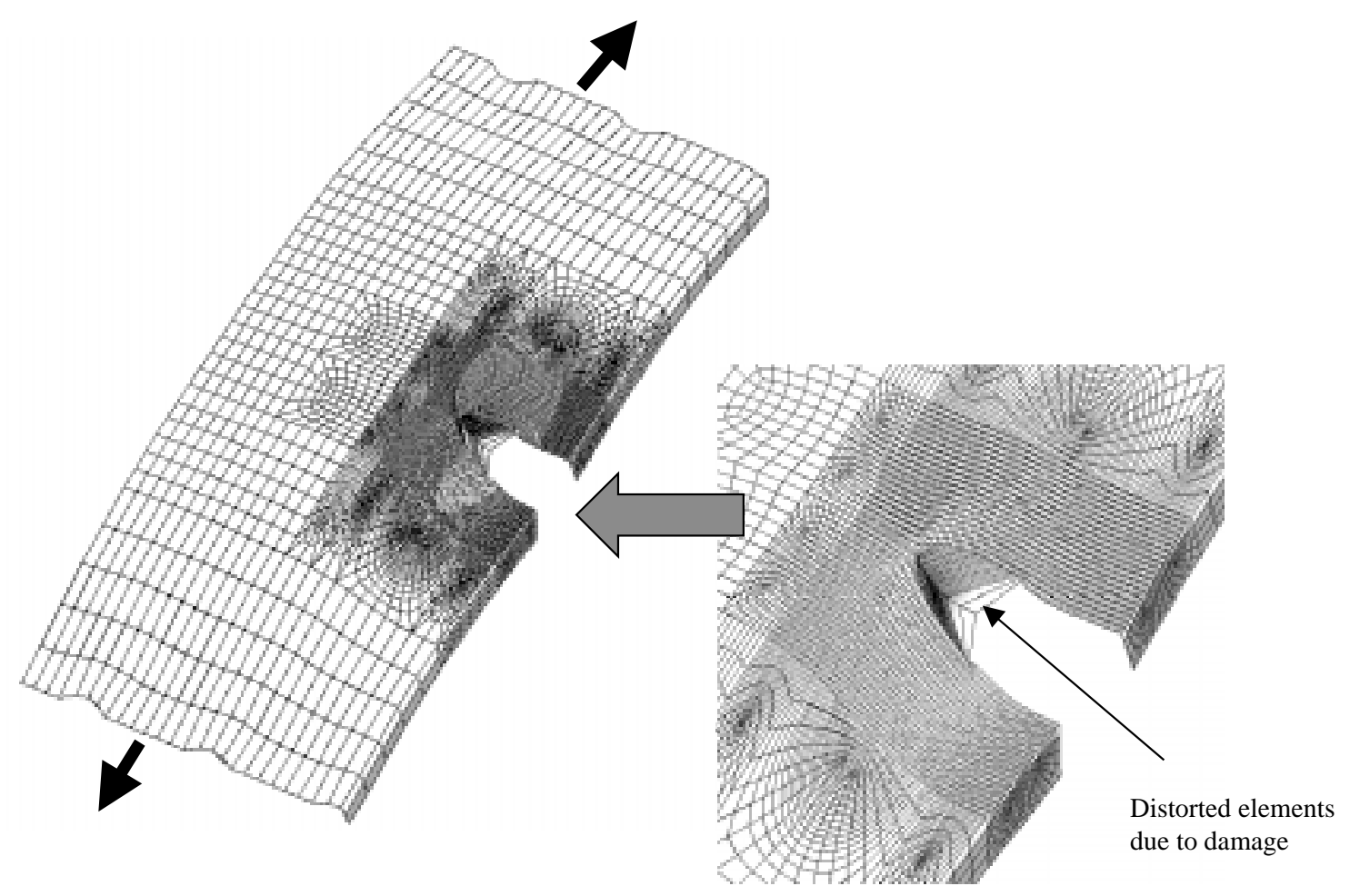

Figure 7. Deformed shape and local damage zone. 
AIAA Paper 99-1336

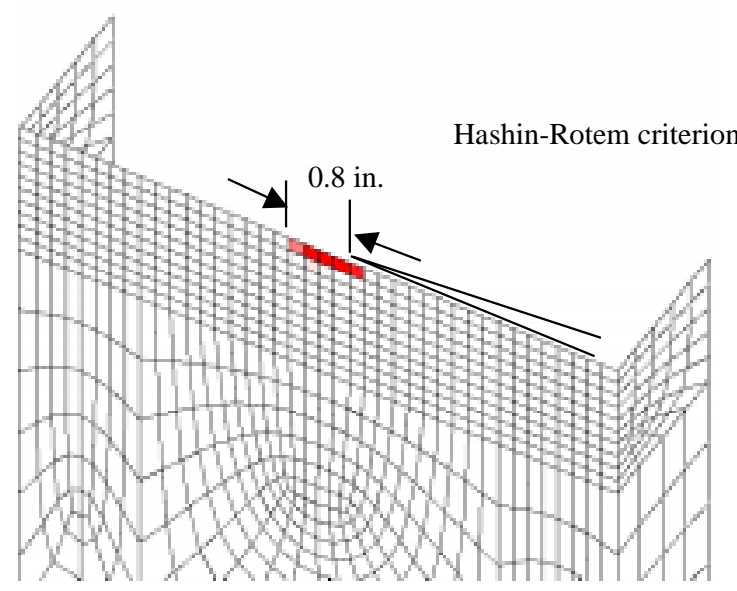

Coarse mesh crack model, 488 kips

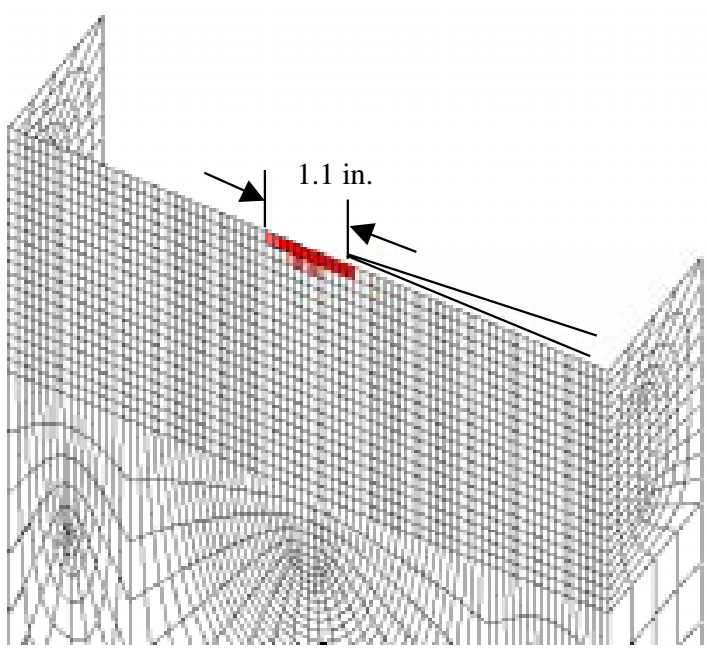

Fine mesh crack model, 485 kips

Figure 8. Damage growth advancing faster for the fine mesh model.

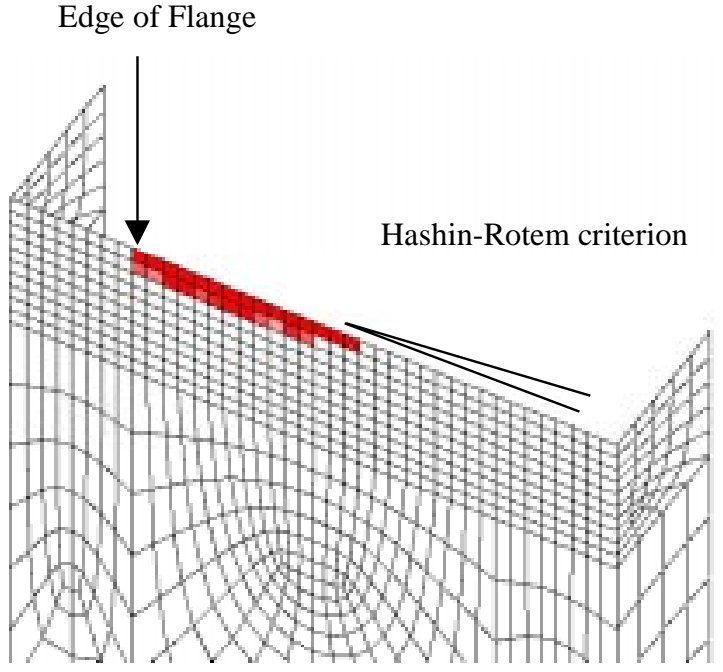

Coarse mesh crack model, 588 kips
Edge of Flange

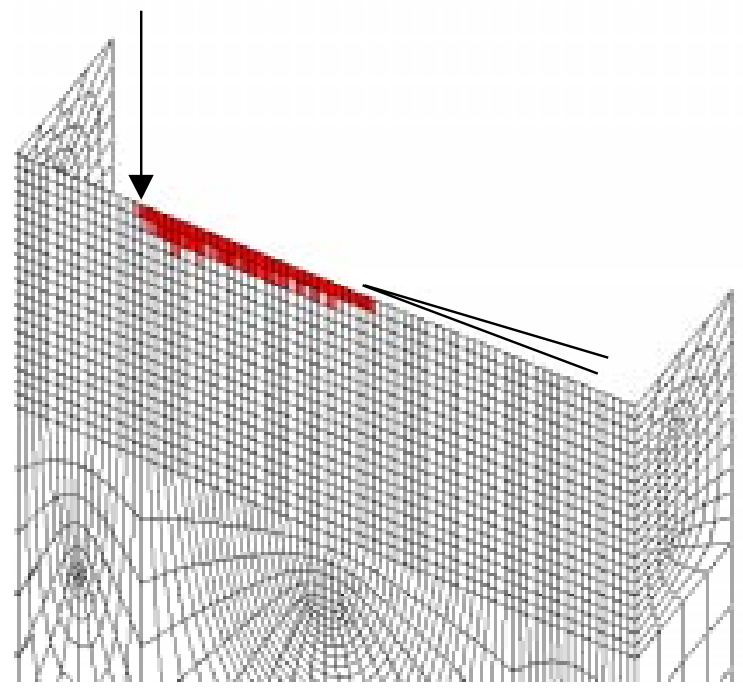

Fine mesh crack model, 564 kips

Figure 9. Applied load level predicted by the coarse mesh higher than that predicted by the fine mesh model. 
AIAA Paper 99-1336

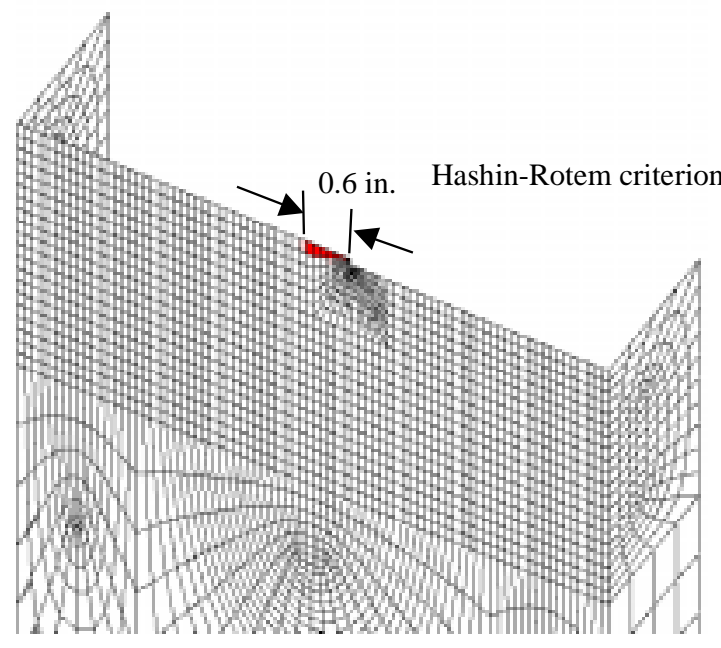

Fine mesh slit model, 363 kips

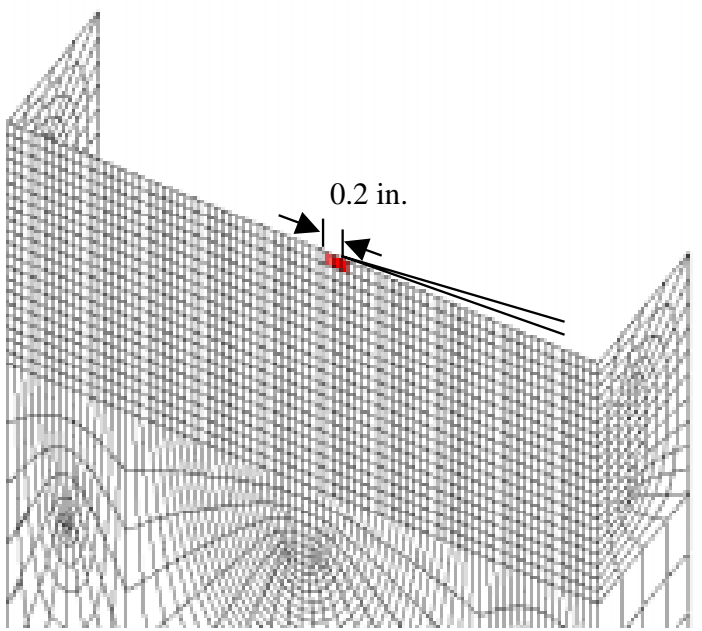

Fine mesh crack model, 369 kips

Figure 10. Damage growth advancing faster in the fine slit model at the initiation stage.

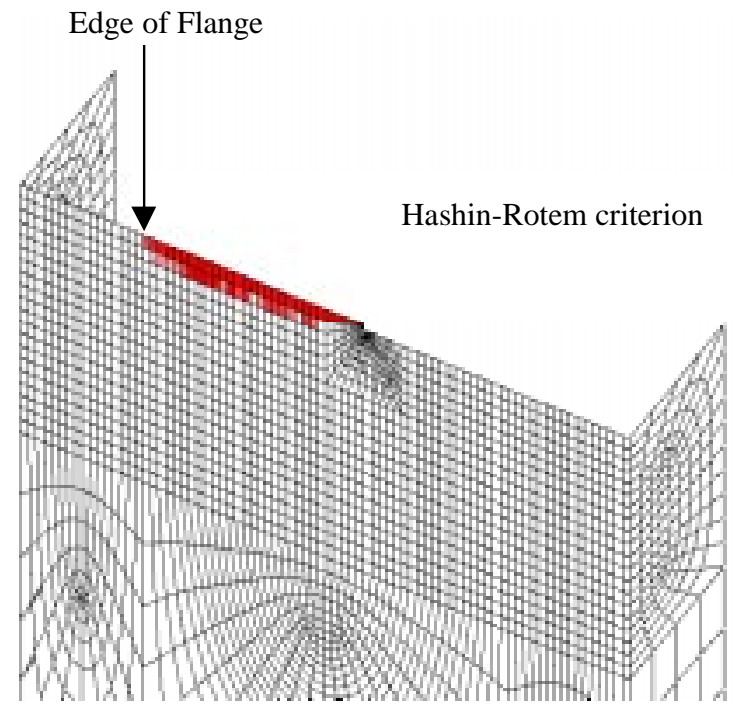

Fine mesh slit model, 522 kips

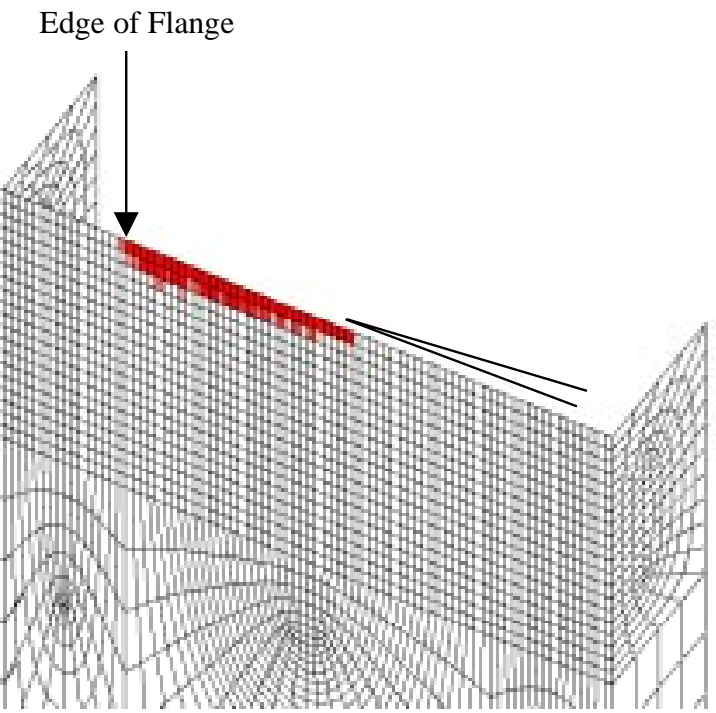

Fine mesh crack model, 564 kips

Figure 11. Applied load level predicted by the fine slit model lower than the fine crack model. 
AIAA Paper 99-1336

Edge of Flange

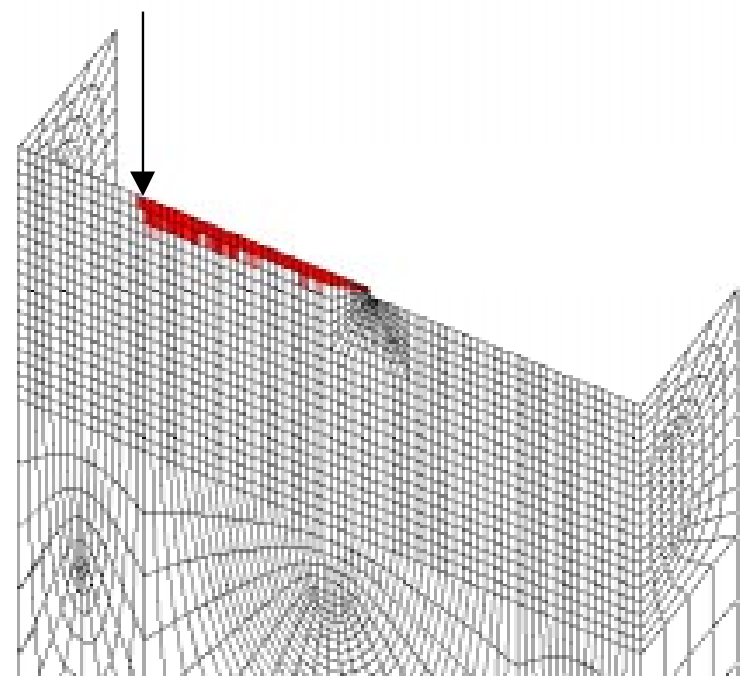

Hashin criterion, 487 kips
Edge of Flange

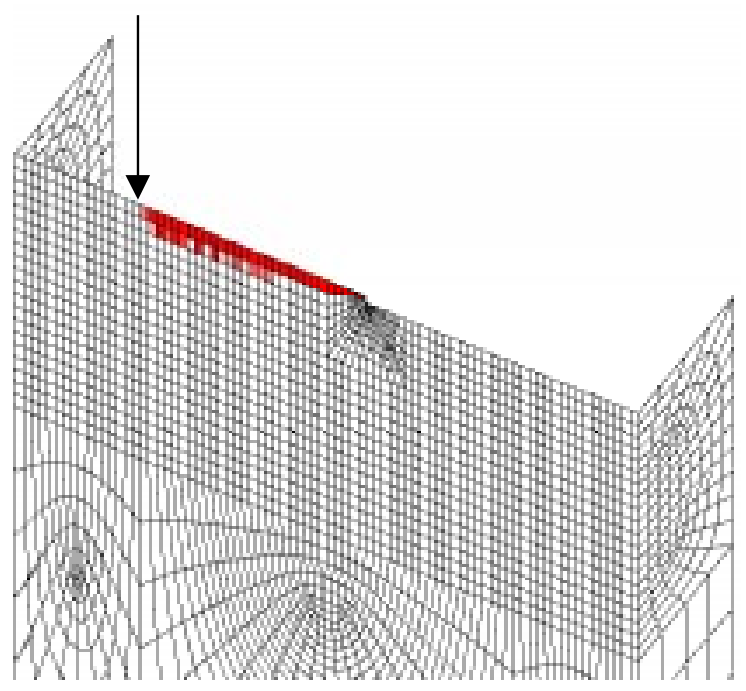

Maximum stress criterion, 547 kips

Figure 12. Applied load level predicted by the Hashin criterion lower than that by the Maximum Stress criterion.

Edge of Flange

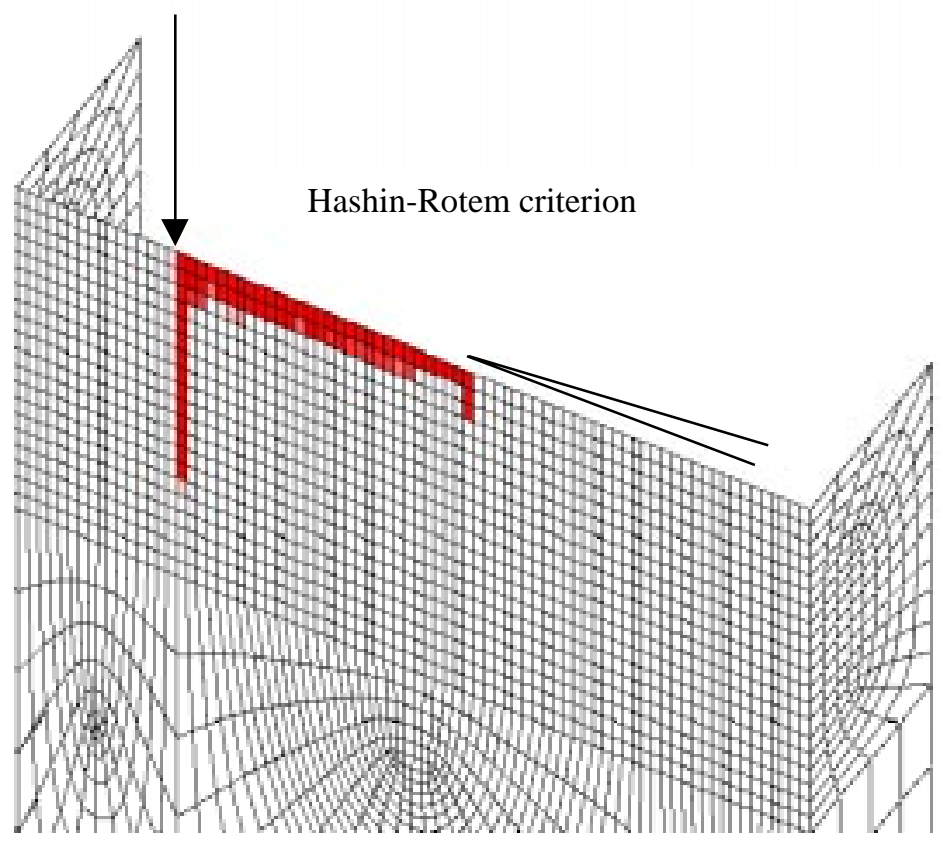

Figure 13. Crack turning due to using high strength material in the flange. 